\title{
Uncertainty of the stratospheric/tropospheric temperature trends in 1979-2008: multiple satellite MSU, radiosonde, and reanalysis datasets
}

\author{
J. Xu' ${ }^{1}$ and A. M. Powell Jr. ${ }^{2}$ \\ ${ }^{1}$ Environmental Science and Technology Center, College of Science, George Mason University, Fairfax, VA 22030, USA \\ ${ }^{2}$ Center for Satellite Application and Research (STAR), USA
}

Received: 28 April 2011 - Published in Atmos. Chem. Phys. Discuss.: 14 June 2011

Revised: 18 October 2011 - Accepted: 20 October 2011 - Published: 28 October 2011

\begin{abstract}
The trends and spreads of tropospheric and stratospheric temperature are discussed in terms of three groups of datasets in 1979-2008. These datasets include (a) three satellite observations of Microwave Sounding Units (MSU) measurements, (b) five radiosonde observations and (c) five reanalysis products. The equivalent tropospheric and stratospheric temperature from radiosonde and reanalyses are calculated based on the vertical weighting function of the MSU channel $2(\mathrm{CH} 2)$ and channel $4(\mathrm{CH} 4)$ measurements, respectively. The results show that both cooling in the stratosphere and warming in troposphere significantly depends on the datasets and latitudes.
\end{abstract}

\section{Introduction}

Except that the radiosonde observations are currently used in the estimates of climate change, the satellite observations from the Microwave Sounding Units (MSUs) and Advanced Microwave Sounding Units (AMSUs) have become one of the important data sources for climate analysis (Santer et al., 1999; Fu et al., 2004). Satellite instruments not only provide data up to the upper stratosphere $(50 \mathrm{~km})$, but also cover the ocean and polar areas. Satellite observations overcome to some extent the shortcoming in the radiosonde observations. Unfortunately, similar to the shortcoming in the radiosonde observations, the number of satellite instruments and changes in design impact observational practices and the application of the data. For example, the MSU data come from 12 different satellites and the data quality is significantly affected by intersatellite biases, uncertainties in each instrument's calibration coefficients, changes in instrument body temperature,

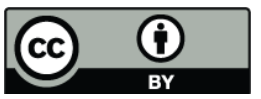

Correspondence to: J. Xu

(jianjun.xu@noaa.gov) drift in sampling of the diurnal cycle, roll biases and decay of orbital altitude (Christy and Spencer, 2000; Zou et al., 2008). Many previous studies (Santers et al., 1999; Seidel et al., 2004; Xu and Powell, 2010; and many others) show that climate analysis depends critically on the selection and implementation of the data sources. The radiosonde datasets exhibit stratospheric cooling trends significantly larger than that in the satellite data (Seidel et al., 2004 ).

The satellite datasets are available since end of 1978 and have been implemented in the reanalysis data assimilation system. The reanalysis products (such as, NCEP-NCAR, NCEP-DOE, ERA-40, MERRA, JRA25, NCEP-CFSR) generally reproduced the global climate variability although with pronounced uncertainty among different reanalyses (Yan et al., 2011), such as EL Nino-Southern Oscillation associated physical processes (Kumar and $\mathrm{Hu}, 2011$, and references therein). These reanalysis products have also been using in climate prediction as initial condition and in its validation as observations. However, the products exhibit a number of uncertainties and limitations. Several deficiencies have been found in the reanalysis datasets (Trenberth, 2001 and many others). In order to quantify the uncertainties in the estimates of the temperature trend for the various data source, an approach (Xu and Powell, 2010) was introduced to address the ensemble spread that discussed the temperature trend and spread in the five radiosonde datasets and seven reanalysis products beginning in 1989. The results show that the spread increases significantly with atmospheric height. The spread in the reanalysis datasets is much larger than the radiosondes in the stratosphere. In contrast, the spread in both reanalysis and radiosonde datasets is very small and shows the trend in better agreement with each other in the troposphere.

Different from the previous study (Xu and Powell, 2010), this study attempts to examine quantitatively the uncertainty in estimates of the temperature trends changing with latitudes among the MSU, radiosonde and reanalysis since 1979 based

Published by Copernicus Publications on behalf of the European Geosciences Union. 
on the measurement of the ensemble spread. Section 2 describes the datasets used in this study, Sects. 3 and 4 presents the trends and spreads as a function of latitude in the stratosphere and troposphere, respectively. Section 5 provides a final summary.

\section{Data and calculation}

To understand the change of temperature trends in the stratosphere and troposphere, the data used in this study include three MSU measurements, five radiosonde observations and five reanalysis products. All datasets spanned the period 1979 through 2008. In order to be consistent with the radiosonde data sets location, the annual data is then processed by zonal-mean for land coverage only. The ERA-40 and ERA-interim used in our previous study (Xu and Powell, 2010) were not employed because of their mismatch with the coverage period.

\subsection{Satellite MSU datasets}

UAH MSU. The first MSU temperature dataset (Christy et al., 2000) was created by Christy's group at the University of Alabama in Huntsville (UAH) based on 12 different satellites. The data used in this study includes the UAH MSU data for the lower stratosphere (MSU channel 4: $\mathrm{CH} 4$ ) and troposphere (MSU channel 2: $\mathrm{CH} 2$ ). The updated version 5.1 includes AMSU data, and incorporates a different (nonlinear rather than linear) correction for time-varying sampling of the diurnal cycle by the MSU instruments due to drift in the local equatorial crossing time of the satellite orbits.

RSS MSU. The second MSU temperature dataset (Mears et al., 2003) was created by Remote Sensing Systems, Inc. (RSS) using different corrections and merging procedures than those used by UAH. This monthly, gridded, global temperature anomaly dataset covers the lower stratosphere (MSU channel 4), and troposphere (MSU2) for this study.

STAR MSU. The third MSU temperature dataset (Zou et al., 2008) was created by Zou's group at Center for Satellite Applications and Research (STAR) in NOAA. In order to reduce the biases in the intersatellite MSU instruments, Zou et al. (2008) developed an intercalibration method based on the simultaneous nadir overpass (SNO) matchups. Due to orbital geometry, the SNO matchups are confined to the polar region where the brightness temperature range is slightly smaller than the global range.

\subsection{Reanalysis datasets}

The five reanalysis products used in this study include NCEP-NCAR, NCEP-DOE, NCEP-CFSR, JRA-25 and
MERRA. More information about these reanalysis products can be found in authors' previous publication (Xu and Powell, 2010).

\subsection{Radiosonde datasets}

The five radiosonde datasets used in this study include HadAT2, RATPAC, IUK, RAOBCORE and RICH. More information about these radiosonde products can be also found in authors' previous publication (Xu and Powell, 2010).

\subsection{Trend and spread calculation}

For each individual monthly dataset listed above, annuallyaveraged data is first computed. The annual data is then processed by zonal-mean. Finally, annual zonal-mean data is interpolated with the same resolution for 10 latitudes.

Generally, the MSU CH4 monitors atmospheric microwave emissions from $150 \mathrm{hPa}$ to $30 \mathrm{hPa}$ with peak at $87 \mathrm{hPa}$ in lower stratosphere, and the MSU CH2 represents the middle tropospheric temperature from $850 \mathrm{hPa}$ to $250 \mathrm{hPa}$ with peak at $600 \mathrm{hPa}$. To facilitate inter-comparison, the pressure-level radiosonde and reanalysis data are processed based on the vertical weighting function of the MSU measurements.

The trend is calculated by the fitting of linear least squares. The ensemble spread is defined by the standard deviation based on the three MSU measurements, five radiosondes and five reanalysis datasets. The t-test analysis was employed to calculate the statistical significance of the temperature trends.

\section{Stratosphere}

Figure $1 \mathrm{a}$ and $\mathrm{b}$ shows the stratospheric temperature $\left(T_{\mathrm{CH} 4}\right)$ trend changes with latitude in the MSU, radiosonde and reanalysis datasets in 1979-2008. To best understand the different trends in the multiple data sources, the same results are plotted by two ways: a latitude profile for each individual dataset (Fig. 1a) and as a latitude section to facilitate comparing regions between the datasets (Fig. 1b). The results indicate that the linear trends are highly sensitive to the data sources and the latitudes of interest. All exhibit predominant cooling in the stratosphere, except for the JRA-25 in the southern middle latitudes. There is a strong cooling trend in all datasets over the tropics and subtropics $\left(40^{\circ} \mathrm{S}-40^{\circ} \mathrm{N}\right)$.

For the satellite MSU (RSS, UAH and STAR in Fig. 1) $\mathrm{CH} 4$ datasets, the trend in the UAH MSU data shows different features from RSS and STAR. Over the tropics, the trends $\left(-0.4 \mathrm{Kdecade}^{-1}\right)$ in the three MSU datasets match quite well. However, the magnitude of cooling of approximately $-0.5 \mathrm{~K} \mathrm{decade}^{-1}$ in UAH is lower than the value in RSS and STAR over both southern and northern middle latitudes. Over the Arctic, the cooling trend is $-0.3 \mathrm{~K} \mathrm{decade}^{-1}$ in $\mathrm{UAH}$, while the trends are $-0.03 \mathrm{~K}_{\text {decade }}{ }^{-1}$ in STAR and 


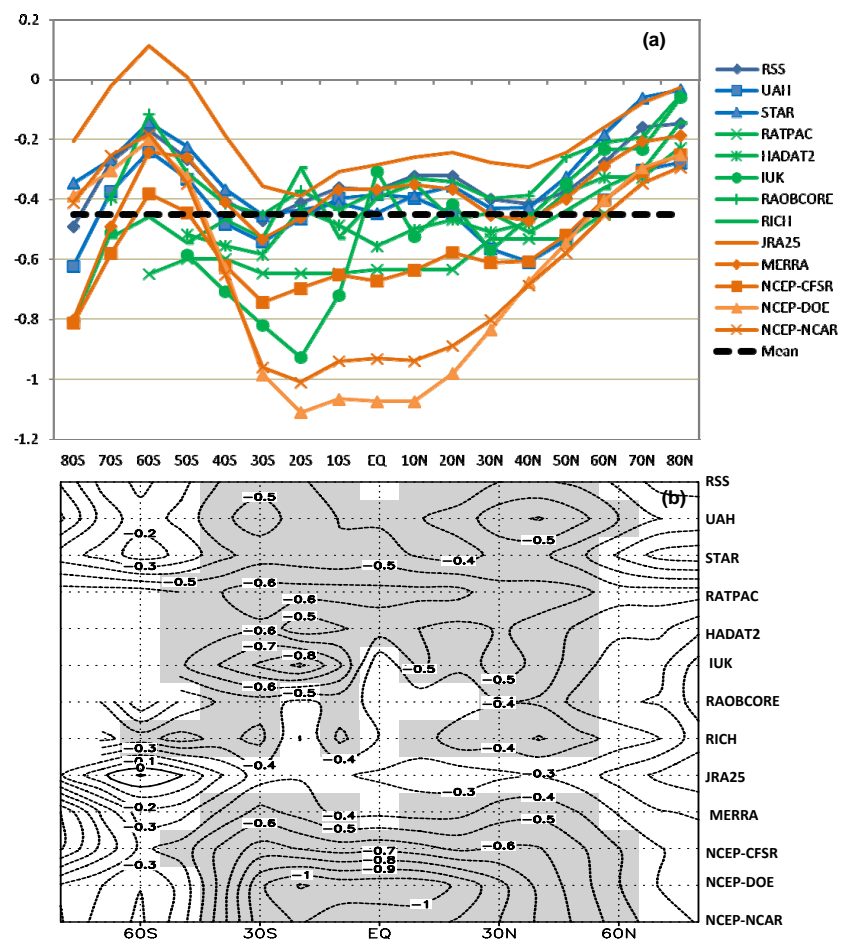

Fig. 1. Inter-comparison of stratospheric temperature $\left(T_{\mathrm{CH} 4}\right)$ trends ( decade $^{-1}$ ) for the MSU (RSS, UAH, STAR), Radiosonde (RATPAC, HADAT2, UK, RAOBCORE, RICH) and Reanalysis (JRA25, MERRA, NCEP- CFSR, NCEP-NCAR, NCEP-DOE) products for the period of 1979-2008. (a) Trend changes with latitude for each individual dataset; (b) latitude sections by data source for the trends - the shaded areas indicated the statistical significance t-test at the $99 \%$.

$-0.14 \mathrm{~K} \mathrm{decade}^{-1}$ in RSS. Over Antarctica, the strongest cooling trend of $-0.62 \mathrm{~K} \mathrm{decade}^{-1}$ is found in $\mathrm{UAH}$, while cooling is observed around $0.48 \mathrm{Kdecade}^{-1}$ in RSS and $-0.35 \mathrm{~K} \mathrm{decade}^{-1}$ in STAR.

For the radiosonde (RATAPC, HADAT2, IUK, RAOBCORE, RICH) datasets, the trend in RATAPC, HADAT2, IUK is approximately $-0.2 \mathrm{~K} \mathrm{decade}^{-1}$ cooler than its counterpart in MSU observations in the tropics. The strongest cooling of $-0.93 \mathrm{~K} \mathrm{decade}^{-1}$ is observed at $20^{\circ} \mathrm{S}$ in IUK, which is consistent with previous results (Seidel et al., 2004). The trends in RAOBCORE and RICH show a similar magnitude as the MSU measurements, except for the RICH which shows a slightly cooler trend at $10^{\circ} \mathrm{S}$. Over the Arctic, weak cooling is found in all five radiosonde observations. Over the Antarctic, the available data shows a trend from $-0.4 \mathrm{~K} \mathrm{decade}^{-1}$ in RAOBCORE to $-0.8 \mathrm{~K} \mathrm{decade}^{-1}$ in IUK. Note that the temperature trends in the Antarctic need be considered carefully because of infrequent observations. In addition, trends in Antarctica below approximately $600 \mathrm{hPa}$ reflect adiabatic extrapolation to higher pressure levels since the elevations are above $3000 \mathrm{~m}$.

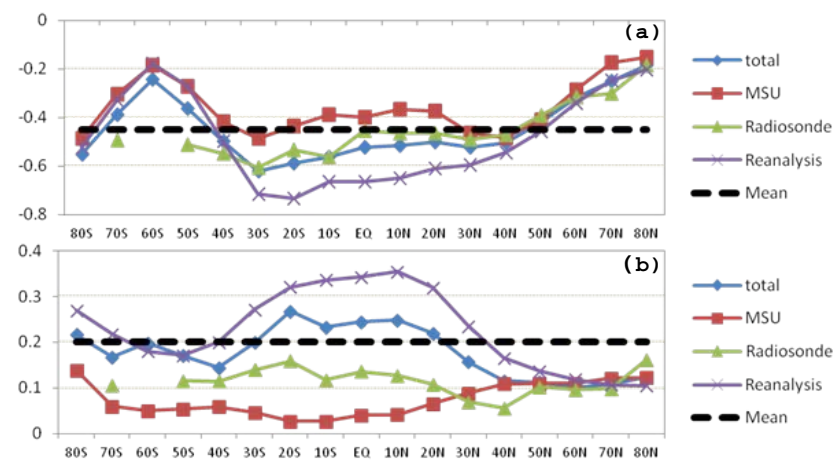

Fig. 2. Stratospheric temperature $\left(T_{\mathrm{CH} 4}\right)$ trends $\left(\mathrm{Kdecade}^{-1}\right)$ (a) each group mean; (b) spread for each group . Note that the "total" is MSU + Radiosonde + reanalysis; the "mean" is the global average for all thirteen datasets.

For the reanalysis (JRA25, MERRA, NCEP-CFSR, NCEP-NCAR, NCEP-DOE ) datasets, the JRA25 shows an exceptional feature where a very weak cooling trend is observed in most latitudes, with a weak warming trend over $50-60^{\circ} \mathrm{S}$. Over the tropics, the trends in both NCEPNCAR and NCEP-DOE reanalysis are much cooler than the other eleven datasets. The strongest cooling exceeds $-1 \mathrm{~K} \mathrm{decade}^{-1}$ at $20^{\circ} \mathrm{S}$ in the NCEP-DOE. A cooling trend of $-0.6 \mathrm{~K} \mathrm{decade}^{-1}$ in the NCEP new reanalysis (NCEPCFSR) is close to the radiosonde observation in RATAPC, but it is $-0.2 \mathrm{~K} \mathrm{decade}^{-1}$ cooler than the trends in the three MSU datasets. In contrast, the trend of $-0.4 \mathrm{~K} \mathrm{decade}^{-1}$ in MERRA is pretty similar to the cooling in the MSU observation. Over the Arctic, there is a similar cooling in the four reanalysis datasets except for the JRA25. Over Antarctica, a slightly stronger cooling is observed in the NCEP-CFSR and MERRA, which equals the trend in the MSU RSS and UAH. However, a weak cooling is found in the NCEP-NCAR and NCEP-DOE datasets. The shaded areas with $t$ value of 2.5 denote (Fig. 1b) statistically significant cooling trend above the $99 \%$ level in tropics and middle latitudes except for the JRA25 reanalysis, but the large stratospheric cooling trend in both polar areas are not statistically significant.

Figure $2 \mathrm{a}$ and $\mathrm{b}$ shows the temperature trend and spread changes with latitude for the thirteen datasets. The trends demonstrate a pronounced difference between low- and highlatitude (Fig. 2a). The total-mean trend changes from strongest cooling $\left(-0.6 \mathrm{Kdecade}^{-1}\right)$ at the southern subtropics $\left(\sim 30^{\circ} \mathrm{S}\right)$ to weakest cooling $\left(\sim-0.2 \mathrm{~K} \mathrm{decade}^{-1}\right)$ at the Arctic. Over the tropics-subtropics $\left(40^{\circ} \mathrm{S}-40^{\circ} \mathrm{N}\right)$, the trend is lower than the magnitude of global mean trend $\left(-0.44 \mathrm{~K} \mathrm{decade}^{-1}\right)$. The mean trend in the five reanalyses are $-0.1 \mathrm{~K} \mathrm{decade}^{-1}$ cooler than the magnitude in the five radiosonde datasets, while it is $-0.2 \mathrm{~K} \mathrm{decade}^{-1}$ cooler than that in the three MSU datasets. Over both middle-high latitudes, except for the Antarctic, the cooling trend is higher than the global mean, and the trends agree very well with the three groups of datasets. 


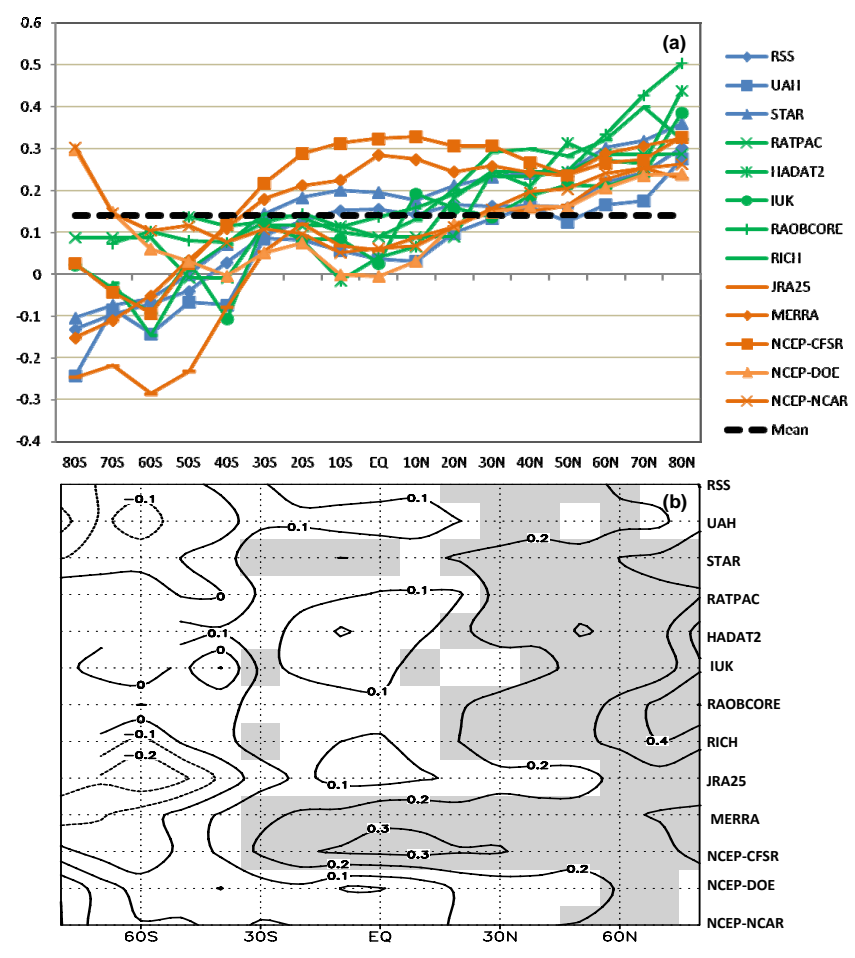

Fig. 3. Similar to the Fig. 1 except for the tropospheric temperature $\left(T_{\mathrm{CH} 2}\right)$ trends.

Consistent with the distribution of trends, the spread of all the MSU, radiosonde and reanalysis datasets change substantially with latitude from $\sim 0.1 \mathrm{~K} \mathrm{decade}^{-1}$ in the northern high-latitude to $\sim 0.25 \mathrm{~K} \mathrm{decade}^{-1}$ in the tropics (Fig. 2b). The spread in the five reanalysis gets up to $0.35 \mathrm{~K} \mathrm{decade}^{-1}$, and the value is much higher than its counterpart in both the radiosonde and MSU datasets in the tropics-subtropics. The spread for the three group datasets shows a similar rate of $0.1 \mathrm{~K} \mathrm{decade}^{-1}$ in the northern middle-high latitudes. In contrast, there are some remarkable differences among the MSU, reanalysis and radiosonde datasets in the southern middlehigh latitudes. It is worth noting that the spread in MSU datasets shows a smaller value in all latitudes when compared to the other two groups of datasets. The larger spread in the reanalyses reflects the influence of different data assimilation systems. It is clear that the cooling trends of the stratospheric temperature markedly changes with latitude, the largest magnitude in both trend and spread is found in the tropicssubtropics $\left(40^{\circ} \mathrm{S}-40^{\circ} \mathrm{N}\right)$. The spread in the southern middlehigh latitudes is $0.1 \mathrm{~K} \mathrm{decade}^{-1}$ larger than that in the northern middle-high latitudes. The trend and spread significantly depends on data sources, assimilation techniques, and the models used. The JRA25 shows a very weak cooling trend over most latitudes. The NCEP-DOE and NCEP-NCAR has the coldest trend on the order of $-1.0 \mathrm{~K} \mathrm{decade}^{-1}$, and the magnitude exceeds a doubling of the global mean trend $\left(-0.44 \mathrm{~K} \mathrm{decade}^{-1}\right)$. Both the coldest trend and the largest

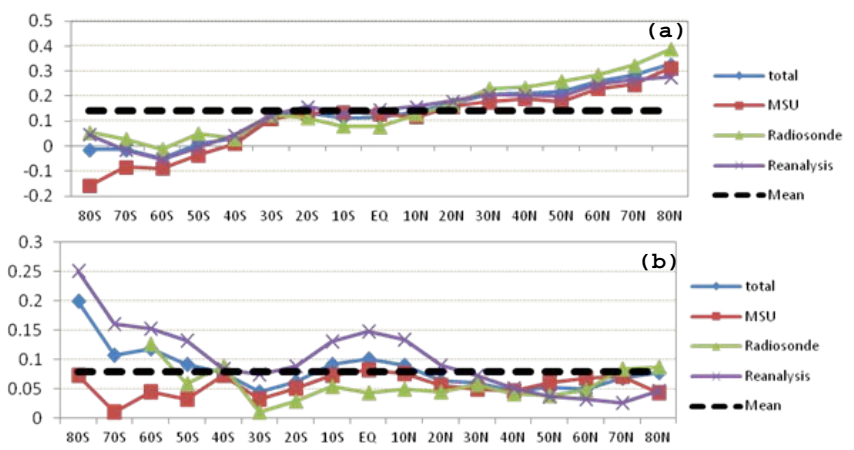

Fig. 4. Similar to the Fig. 2 except for the tropospheric temperature $\left(T_{\mathrm{CH} 2}\right)$ trends.

spread are found in the reanalysis datasets. The MSU observations have the smallest trend and spread of the three groups of datasets.

\section{Troposphere}

Based on the tropospheric temperature $\left(T_{\mathrm{CH} 2}\right)$, in contrast, all the datasets indicate (Fig. 3) a significant warming in the troposphere, except for the Antarctic. Trends in the Arctic are substantially different from the Antarctic. The warming trend increased with latitude from the South to North.

For the satellite MSU CH2 datasets (Fig. 3a and b), UAH shows a different trend from RSS and STAR. Over the tropics, the warming trend from UAH is approximately $0.1 \mathrm{~K}_{\text {decade }}{ }^{-1}$ lower than the other two MSU datasets. Over Antarctica, the cooling trend is $-0.15 \mathrm{~K} \mathrm{decade}^{-1}$ in $\mathrm{UAH}$, while the trends are $-0.09 \mathrm{Kdecade}^{-1}$ in STAR and $-0.07 \mathrm{~K} \mathrm{decade}^{-1}$ in RSS. Over the Arctic, the strongest warming in the rate of $0.3 \mathrm{Kdecade}^{-1}$ is found in STAR, while warming is observed around $0.25 \mathrm{~K} \mathrm{decade}^{-1}$ in RSS and $0.15 \mathrm{~K} \mathrm{decade}^{-1}$ in UAH.

For the radiosonde datasets, a remarkable warming center appears in the Arctic with the strongest magnitude on the order of $0.5 \mathrm{~K} \mathrm{decade}^{-1}$ in RAOBCORE. The warming trend is approximately $0.1-0.2 \mathrm{~K} \mathrm{decade}^{-1}$ higher than its counterpart in the MSU observations over all latitudes.

For the reanalysis datasets, a pronounced change is observed where a slightly stronger warming appears in the MERRA and NCEP-CFSR in the tropics. The maximum warming trend exceeds $0.3 \mathrm{Kdecade}^{-1}$ in NCEP-CFSR. Over Antarctica, JRA-25, MERRA and NCEP-CFSR repeat the cooling trend observed in the three MSU observations, with the strongest cooling trend getting up $-0.2 \mathrm{~K} \mathrm{decade}^{-1}$ in JRA-25. The other two NCEP reanalyses show opposite trends. Over the Arctic, there is a similar warming in the five reanalysis datasets. The warming trend magnitude is between the radiosonde and MSU observations. 
The statistically significant test shows that the warming trends exceed the confidence at the $99 \%$ level over the northern middle-high latitudes in all datasets. In contrast, all trends over the southern middle-high latitudes are not statistically significant. Over the tropics, there are trends in the RSS, STAR of the MSU, the RAOBCORE of the radiosonde and the MERRA, NCEP-CFSR of the reanalysis going through the significant test at the $99 \%$ level.

Compared to its counterparts in the stratosphere, the trend and spread show a noticeable different characteristic in troposphere (Fig. 2a and b vs. Fig. $4 a$ and b). The three group datasets show a similar warming trend increasing with latitude from south to north (Fig. 4a). The magnitude of the warming trend is higher than the global mean (dished line in Fig. 4a) northward of $20^{\circ} \mathrm{N}$, while the trend is lower than the global mean southward of $30^{\circ} \mathrm{S}$, the Antarctic appears to have a cooling trend. Generally, the trend in the reanalysis is higher than the MSU measurements and lower than the radiosonde observations. The coherent spread exhibits (Fig. 4b) a larger difference in the reanalysis in the tropical and Southern Hemisphere, especially, where the maximum value gets up to $0.25 \mathrm{~K} \mathrm{decade}^{-1}$ over Antarctica. The spread in the radiosondes is the smallest one of the three groups of datasets in the tropics, while the smallest spread is observed in the reanalysis in the northern high-latitudes.

To summarize, a common feature was found where the warming trend increases with latitude from south to north in the troposphere. The warmest trend appears over the Arctic with the spread increasing in the opposite direction and the largest spread emerging over the Antarctic. In addition, the magnitude of the trends and spreads depend significantly on the data sources. Over Antarctica, the cooling trends are observed in MSU measurements and JRA-25, MERRA and NCEP-CFSR reanalyses. The smallest spread is found in the MSU observations. Over the tropics, the warmest trend is observed in the NCEP-CFSR reanalysis and the smallest spread appears in the radiosonde datasets. Over the Arctic, the RAOBCORE has the warmest trend, and the reanalysis products show the smallest spread.

\section{Conclusions}

Based on the three groups of datasets including (a) three sets of satellite Microwave Sounding Unit measurements, (b) five sets of radiosonde observations and (c) five reanalysis products in 1979-2008, the tropospheric and stratospheric temperature trend and spread are discussed. The results are indicated as follows:

1. In the stratosphere, a pronounced cooling trend was found with a larger spread appearing over the tropicssubtropics $\left(40^{\circ} \mathrm{S}-40^{\circ} \mathrm{N}\right)$. This is a very consistent for all datasets over the northern middle-high latitudes. However, the trend and spread shows a remarkably different feature in the three groups of datasets. The radiosonde has a larger magnitude cooling trend and spread than the MSU data, while it is smaller than the reanalysis. The NCEP-DOE and NCEP-NCAR datasets with a rate of $-1.0 \mathrm{~K} \mathrm{decade}^{-1}$ have a much colder trend than any other products with a range from -0.3 to $-0.7 \mathrm{Kdecade}^{-1}$ over the tropics. The spread in the reanalysis datasets $\left(0.35 \mathrm{~K} \mathrm{decade}^{-1}\right)$ is around seven times greater than the value in the MSU $\left(0.05 \mathrm{~K} \mathrm{decade}^{-1}\right)$. The JRA25 shows a noticeable inconsistency compared to the other twelve datasets.

2. In the troposphere, a common feature is found where the warming trend increases with latitude from south to north and the spread increases in the opposite direction with the largest spread emerging over the Antarctic. In addition, the magnitude of the trend and spread significantly depends on the data sources. Over Antarctica, cooling trends are observed in MSU measurements and JRA-25, MERRA and NCEP-CFSR reanalysis with the smallest spread found in the three MSU measurements. Over the tropics, the warmest trend is observed in the NCEP-CFSR reanalysis and the smallest spread appears in the radiosonde datasets. Over the Arctic, the RAOBCORE has the warmest trend and the five reanalysis products show the smallest spread.

In general, greater consistency is needed between the various data sets before a climate trend can be established in any region that would provide the reliability expected of a trusted authoritative source.

Acknowledgements. This work was supported by the National Oceanic and Atmospheric Administration (NOAA), National Environmental Satellite, Data, and Information Service (NESDIS), Center for Satellite Applications and Research (STAR). The views, opinions, and findings contained in this publication are those of the authors and should not be considered an official NOAA or US Government position, policy, or decision.

Edited by: M. Dameris

\section{References}

Christy, J. R., Spencer, R. W., and Braswell, W. D.: MSU tropospheric temperatures: Dataset construction and radiosonde comparisons, J. Atmos. Oceanic Technol., 17, 1153-1170, 2000.

Fu, Q., Johanson, C. M., Warren, S. G., and Seidel, D. J.: Contribution of stratospheric cooling to satellite-inferred tropospheric trends, Nature, 429, 55-58, 2004.

Kumar, A. and Hu, Z.-Z.: Uncertainty in the ocean-atmosphere feedbacks associated with ENSO in the reanalysis products, Clim. Dynam., doi:10.1007/s00382-011-1104-3, online first, 2011.

Mears, C. A., Schabel, M. C., and Wentz, F. J.: A reanalysis of the MSU channel 2 tropospheric temperature record, J. Climate, 16, 3650-3664, 2003. 
Santer, B. D., Hnilo, J. J., Wigley, T. M. L., Boyle, J. S., Doutriaux, C., Fiorino, M., Parker, D.E., and Taylor K. E.: Uncertainties in observationally based estimates of temperature change in the free atmosphere, J. Geophys. Res., 104, 6305-6333, 1999.

Seidel, D. J., Angell, J. K., Christy, J., Free, M., Klein, S. A., Lanzante, J. R., Mears, S. C., Parker,D., Schabel, M., Spencer, R., Sterin, A., Thorne, P., and Wentz, F.: Uncertainty in signals of large-scale climate variations in radiosonde and satellite upperair temperature datasets, J. Climate, 17, 2225-2240, 2004.

Trenberth, K. E., Stepaniak, D. P., Hurrell, J. W., and Fiorino, M.: Quality of reanalyses in the tropics, J. Climate, 14, 1499-1510, 2001.
Xu, J. and Powell, A. M.: Ensemble spread and its implication for the evaluation of temperature trends from multiple radiosondes and reanalyses products, Geophys. Res. Lett., 37, L17704, doi:10.1029/2010GL044300, 2010.

Xue, Y., Huang, B., Hu, Z.-Z., Kumar, A., Wen, C., Behringer, D., and Nadiga, S.: An assessment of oceanic variability in the NCEP Climate Forecast System Reanalysis, Clim. Dynam., doi:10.1007/s00382-010-0954-4, online first, 2011.

Zou, C., Gao, M., and Goldberg, M.: Error structure and atmospheric temperature trends in observations from the microwave sounding unit, J. Climate, 22, 1661-1680, 2009. 